\title{
CRITERIOS ÉTICOS EN LA SOLUCIÓN DE DILEMAS BIOÉTICOS
}

Lourdes Velázquez González*

Recibido: 18.08 .2014

Aprobado: 20.09.2014

\section{RESUMEN}

El principio del mal menor se encuentra ya en la ética clásica (Platón, Aristóteles, los Estoicos), ya que en ella no se afirman valores morales absolutos, sino que se buscan criterios comparativos para elegir entre bienes diferentes. Con el pensamiento cristiano no se admite la existencia ontológica del mal, pero se afirma la existencia del mal moral como mal absoluto (doctrina introducida por San Agustín y que permaneció en la ética y en la teología moral de los siglos posteriores). También se afirmó la existencia de valores absolutos y por lo tanto inviolables (por ejemplo la dignidad de la persona y los derechos humanos).

Con esto cambia el contexto de aplicación del principio del mal menor, ya que un mal moral, o la violación de un valor absoluto, nunca se pueden considerar como "males menores" en comparación con otros males que se podrían así evitar. Todo esto se resume en el principio fundamental que nunca se puede cometer el mal para conseguir un bien. Por consiguiente, se puede correctamente aplicar el principio del mal menor solamente cuando no sea posible suspender la acción y se trata de escoger entre dos males no absolutos. Entonces resulta ser un "criterio" más que un "principio", cuya aplicación tiene que ser cada vez muy limitada y bien definida. Como ejemplos de aplicación en la bioética se mencionan la eutanasia y el aborto (casos en los cuales el principio no se aplica) y los cuidados paliativos (en los cuales se aplica el principio).

PALABRAS CLAVE

Mal menor - Filosofía moral - Teología moral - Bioética -Eutanasia - Aborto - Cuidados paliativos.

\section{ABSTRACT}

The lesser evil principle is already present in classical ethics (Plato, Aristotle, the Stoics) where no absolute moral values are advocated, but criteria are proposed for comparing different goods. With Christian thought the ontological existence of evil is denied, but the existence of moral evil as absolute evil is affirmed (a doctrine introduced by Augustine and then remained permanent in the subsequent moral philosophy and theology). Also the existence of absolute and inviolable values was affirmed (such as the dignity of the person and the human rights). In such a way the context of application of the lesser evil principle changed since the moral evil and the violation of an absolute value can never be considered as a "lesser evil" which could be acceptable in order to avoid greater evils. All this is summarized in the fundamental principle that it is never licit to do an evil to attain a good. Therefore the lesser evil principle can be correctly applied only when the action cannot be suspended and the choice is between two non-absolute evils. Hence it looks like a "criterion" rather than a "principle" that can be applied only in limited and well determined cases. As examples in the domain of bioethics are mentioned the case of euthanasia and abortion (where the principle does not apply), and the case of palliative cares (where it applies).

\section{KEY-WORDS}

Lesser evil - Moral philosophy - Moral theology - Bioethics - Euthanasia - Abortion - Palliative cares

* Doctora en Filosofía Vicepresidenta de la Federación Internacional de Sociedades de Filosofía (FISP).Profesora e investigadora en la Facultad de Bioética de la Universidad Anáhuac, México. Profesora de asignatura en la Universidad Pontificia de México. lourdes.velazquez@anahuac.mx 
El concepto de mal menor se ha convertido en un "principio" evocado con una cierta frecuencia en los debates éticos-jurídi$\cos$ actuales. Aunque no siempre sea clara su naturaleza específica, sobre todo porque no se entiende de una manera unívoca el concepto mismo de mal.

Por otro lado, se trata de un tema que se encuentra ya en la Filosofía clásica antigua; por ejemplo, Platón ya se plantea como puede buscarse el bien mayor y en la República, libro 5, planteó el problema de evaluar lo que es el mayor bien y el mayor mal ${ }^{1}$. Además, en varios diálogos había presentado una jerarquía de los bienes y, por ejemplo, en el Gorgias, Sócrates había afirmado que es mejor sufrir una injusticia que cometer la injusticia². Lo que, en apariencia, ya expresa el principio del mal menor, en realidad veremos más adelante que no es exactamente así.

Aristóteles también se lo plantea cuando discute el problema de la justicia y refiere que en el caso de la justicia hay que comparar un mal menor con un mal mayor (Ética Nicomáquea $\mathrm{V}, 3){ }^{3} \mathrm{Y}$, de manera muy pertinente, apunta que el mal menor nunca se convierte en bien aunque se coloque dentro de la categoría de bien por el hecho que la realización del mal mayor haría perder un bien mucho mayor, así que la comparación siempre se realiza entre bienes y así lo afirma cuando dice: "El mal menor tiene categoría de bien, en relación con un mal mayor. Pues un mal menor es preferible a un mal mayor. $Y$ lo preferible es siempre un bien, y cuanto más preferible es este bien, mayor $\mathrm{es}^{4}$. Es por esto que el planteamiento aristotélico se enmarca dentro de la temática de la argumentación práctica acerca de lo que es preferible para los individuos y para la comunidad (Tópicos, libro III). El problema del mal menor, como podemos darnos cuenta, es en cierto sentido un problema de preferencia de elección. $Y$ esto se identifica plenamente con la ética aristotélica que indica preferiblemente cómo se debe obrar en vista de los fines buenos que se pretendan alcanzar.

Pero fue especialmente con los estoicos que el tema del mal menor entró explícitamente en el campo de los problemas éticos, con Cicerón (De los fines de los bienes y los males y las Disputaciones Tusculanas) y Sénscaif (Cartas a Lucillo, 95, 85) ${ }^{5}$.

Lo que caracteriza el pensamiento filosófico clásico es que en él no se contempla la existencia de valores morales absolutos.

La novedad del pensamiento cristiano consiste precisamente en el haber relacionado la discusión del mal menor con la admisión de valores morales absolutos $y$, por consiguiente, en haber reconocido el carácter de mal absoluto al mal moral. Esto fue posible porque, empezando con San Agustín, se negó una existencia en sentido propio al mal: el mal en cuanto tal no existe, y lo que llamamos mal sólo es una «ausencia o privación de bien», un defectus essendi, ya que todo lo que existe (en cuanto creado por Dios) es de por sí bueno. ${ }^{6}$

El mal moral es algo que se atribuye a una acción humana, cuando el hombre, usando de manera desordenada su libre albedrío, persigue un fin que de por sí tiene algo bueno, pero a costa de sacrificarle un bien de orden superior.

Puestas estas premisas (que toda la teología cristiana ha compartido después), se entiende bien lo que afirma Santo Tomás de Aquino cuando discute explícitamente el tema del mal menor y (siempre tratando del aspecto personal de la acción) subraya que es lícito escoger el mal menor sólo cuando no hay ninguna otra opción posible y los males en cuestión no se pueden evitar. Pero, al mismo tiempo, subraya que el mal moral y el mal considerado como privación de bien no pueden colocarse en el mismo plano (Comentario al libro de las Sentencias, II y IV). ${ }^{7}$

Cfr. Platón. Obras Completas. Editorial Aguilar. Colección grandes culturas, 2da. ed-5ta. reimpresión. Madrid, España. 1981 ISBN 84-03-01002-8

Ibid. , p. 358-59

Aristóteles. Ética Nicomaquea. Editorial Porrúa . Sepan Cuantos, 22 ed. México. 2010. ISBN 978970-07-7212-4

Aristóteles. Obras Completas. Edición trilingüe. Editorial Gredos. Madrid, España. 2001. Justicia. Ret,1368b,7-10

Cfr. Séneca. Cartas morales a Lucilio. Edición a cargo de I .Roca Meliá, Editorial Gredos. Madrid, España 2001.

Agustín San, Obispo de Hipona. La naturaleza del bien en: Obras Completas de S. Agustín. Vol. III, Editorial B.A.C. Madrid, España 1982

Aquino Santo Tomás en: Fernández Clemente, S. Los Filósofos Medievales, Selección de textos, “Comentarios a las Sentencias" de Pedro Lombardo. Ed. B.A.C., Madrid, España 1979, Tomo II, p. 240-267 
En particular los males morales absolutos nunca pueden considerarse un mal menor con respecto a los males y sufrimientos que pueden ser consecuencias de una determinada acción.

Un tratamiento especial del mal menor fue desarrollado en las doctrinas éticas del siglo XV en el contexto de las discusiones acerca de las "dudas de conciencias", que conciernen a la falta de certeza subjetiva cuando de todas maneras no se puede evitar actuar. Dicho estado de incertidumbre fue llamado "conciencia perpleja" y se caracteriza por el hecho que la persona no es capaz de evaluar cuál es el mal menor (por esto hemos dicho que el problema del mal menor tiene un papel importante en este tipo de discusión). Por lo tanto, fue formulado el principio según el cual la persona que, teniendo que escoger entre dos males, no puede suspender su acción y no alcanza a discernir cual es el mal menor, no comete alguna culpa cualquiera que sea su elección, ya que le falta en realidad la verdadera libertad (San-Alfonso María de Ligorio, Teología moral, I, 1, 10). ${ }^{8}$

De todo lo dicho, se puede ver claramente que el criterio del mal menor nunca implica en realidad que se pueda cumplir el mal (aunque sea el menor). En realidad, todo se reduce a una elección entre dos males que de todas maneras son inevitables, ya que nos encontramos en la situación de no poder evitar ni el uno ni el otro, ya que si existiera la posibilidad de abstenernos de la acción tendríamos que hacerlo.
De lo anterior se concluye también que el concepto del mal menor es precisamente, más que un principio, un "criterio" que se aplica en casos bien delimitados y claramente definidos, y dentro del marco del reconocimiento de valores absolutos que, hoy en día, se sintetizan en el concepto de respeto de la dignidad de la persona humana y de los derechos humanos inviolables. De esta manera, el discurso se desplaza del terreno personal al terreno público y se puede admitir que, tomando en cuenta los límites y la fragilidad de la naturaleza humana, el público puede "tolerar" algo no conforme con la verdad y la justicia considerando las consecuencias de ciertos tipos de acciones (sin entrar en el juicio moral acerca de ellas) y aplicando a la evaluación de dichas consecuencias el criterio del mal menor. Sin embargo, la aplicación de este criterio, para ser correcta, presupone que nunca es permitido hacer un mal para que se consiga un bien. Por lo tanto, pasando a considerar las leyes, es muy obvio que ellas no pueden prohibir todo lo que es moralmente malo, pero sí no pueden mandar nada que sea malo. Obviamente este planteamiento es válido si se admite la existencia no sólo de una moral que es independiente y superior a la simple legalidad, sino si además se atribuye a las prescripciones (o por los menos a ciertas prescripciones) de la moral un valor absoluto. Por el contrario, para las éticas relativistas, utilitaristas, subjetivistas, que evalúan la moralidad de una acción en base a sus consecuencias, no se admite aquella diferencia de planes que no permite "comparar" un mal moral con un mal concreto como un daño o un sufrimiento, y, por lo tanto, el criterio del mal menor se convierte en una especie de principio que se presta a todo tipo de abuso (en cuanto falta un criterio objetivo para comparar dichos males).

Sin embargo, el criterio del mal menor se presenta también para los que admiten valores morales absolutos, cuando sean involucrados en la aprobación de ciertas leyes que permiten (legalmente) ciertas acciones que ellos consideran absolutamente malas. En estos casos, el criterio se puede adoptar solamente cuando aplicar una ley menos injusta (en el sentido de permitir acciones moralmente menos malas) sea la única manera para sustituir una ley más injusta.

Pasando a los casos concretos que se encuentran en las discusiones actuales éticas y legales, se pueden distinguir tres ámbitos fundamentales de ambigüedad:

1. Confusión entre bienes y valores morales y otros tipos de bienes (económicos, de salud, de bienestar, etc.). De esta ambigüedad nace la dificultad de reconocer la incomparabilidad de los dos tipos de bienes $y$, por consiguiente, la imposibilidad de reconocer que un mal moral nunca puede ser considerado un mal menor con respecto a otros males presentes en la vida humana y que se podrían evitar cumpliendo la acción moralmente mala. 
2. La falta de distinción entre la bondad o maldad de las consecuencias de la acción y la bondad o maldad de la misma acción. En la ética se han considerado tipos de acción que son intrínsecamente buenas o malas, en base a fundamentos que pueden diferir de una ética a otra (por ejemplo, fundamentos basados en la consideración de la naturaleza humana, o en la estructura del concepto mismo de deber, o en los mandamientos divinos, etc.). $Y$ estos tipos de acción son malos independientemente de las consecuencias que puedan tener. Estas éticas en general se caracterizan por admitir ciertos absolutos morales los cuales, precisamente por ser "absolutos", que significa "incondicionados", no se pueden violar bajo ninguna condición. Sin embargo, es claro que hoy en día son tal vez más escuchadas las voces de éticas que no admiten $a b$ solutos morales y que, cuando no son declaradamente subjetivistas o voluntaristas, aceptan a lo mejor la evaluación de consecuencias en base a criterios casi siempre muy variables e imprecisables.

3. La pérdida del sentido por lo que es preferible escoger algo que es una obligación (mejor dicho, un deber) en lugar de algo que nos parece mejor. Podríamos decir que en esto consiste la atenuación del sentido del deber que caracteriza a nuestra época, la cual no acepta fácilmente la afirmación socrática ya mencionada que es mejor padecer una injusticia que hacerla.
Si quisiéramos ahora considerar algunos ejemplos concretos podríamos empezar, por ejemplo, con el caso de los pacientes terminales que padecen fuertes dolores. En este caso hay una posición que favorece la eutanasia, es decir, el procurar directamente la muerte del paciente afirmando que se trata de un "mal menor" comparado con el perdurar de una vida de sufrimientos destinada a acabarse dentro de poco tiempo. En realidad, no se trata de una aplicación correcta del principio del mal menor, ya que el procurar directamente la muerte (es decir, matar a una persona) es un mal moral que nunca puede considerarse un mal menor con respecto a otros males físicos por fuertes que sean. Pero si se escoge la solución de practicar al paciente tratamientos paliativos, es decir terapias que disminuyen considerablemente el dolor, aunque puedan tener como consecuencia una abreviación de la vida, en este caso sí se puede aplicar el criterio del mal menor. Está claro, sin embargo, que este razonamiento vale si se considera un absoluto moral el no matar a un ser humano.

Similar es el caso del aborto procurado para evitar el nacimiento de un niño malformado. En este caso también no se puede hablar de mal menor y muchos que defienden el aborto, en realidad, lo hacen en base a otros principios éticos que quisieran quitarle el carácter de acción absolutamente mala.

Fuera de la bioética, en todas las dictaduras, las medidas opresivas de la libertad y los derechos humanos se justifican a menudo como males menores para asegurar consecuencias positivas de tipo social, económico y hasta para llegar a una forma futura de sociedad más justa. En este caso también la violación de derechos humanos fundamentales es un mal moral que no puede considerarse como mal menor respeto a las supuestas faltas de ciertas condiciones socio-económicas que se pretenden conseguir. Sin embargo, en este caso, el principio moral que se viola es el según el cual el fin no justifica los medios en el sentido que no se puede cometer un mal para que siga algún bien (como ya hemos visto).

Realidades como los conflictos en Medio Oriente, los atentados terroristas del 11/09 o la Guerra de Irak, han hecho resurgir la denominada "ética en situaciones de emergencia" que se puede considerar una variación sobre el tema del mal menor. Este problema se ha discutido casi siempre en términos más o menos jurídicos, es decir ¿Cómo debe reaccionar un país democrático ante los ataques de células terroristas? ¿Es legítimo violar acuerdos internacionales como los de la Convención de Ginebra o la Convención contra la tortura porque debe responderse a una agresión? En realidad detrás de estas preguntas jurídicas se encuentran cuestiones éticas fundamentales que conciernen al respeto de los derechos humanos. En este caso, también más que una aplicación del criterio del mal menor, se trata del principio que el fin no justifica los medios.

Una apreciación positiva que tenemos que manifestar hacia 
la filosofía y la práctica política detalles y medidas concretas) de la no violencia (sin por otro es el hecho de que en ella se lado suscribirnos a todos sus niega que la violencia pueda ser un mal menor en vista de consecuencias supuestamente positivas. 
